This is the author's version of a work that was submitted to / accepted for publication. To cite this article: Hemming, P. J. 2008. Mixing qualitative research methods in children's geographies. Area 40(2), pp. 152-162. (10.1111/j.1475-4762.2008.00798.x)

\title{
Mixing qualitative research methods in children's geographies
}

Peter J Hemming, School of Geography and School of Sociology and Social Policy, University of Leeds, Leeds LS2 9JT. Email: p.j.hemming06@leeds.ac.uk

\begin{abstract}
Human geographers are increasingly employing mixed-method approaches in their research, including in children's geographies, where 'child-centred' methods are often used alongside participant observation and semi-structured interviews to investigate children's perceptions and experiences. Mixing qualitative methods in this way raises a number of ethical and methodological issues, particularly regarding the changing power relationships between researchers and participants. This article considers the challenges and potential benefits of combining methods from participatory and interpretive approaches through triangulation or 'crystallisation'. The issues are illustrated through an empirical case study on children, health and exercise in the everyday spaces of the primary school.
\end{abstract}

\section{Key words:}

qualitative, mixed-method, children, research, triangulation, United Kingdom 


\section{Introduction}

In human geography, mixed method approaches are increasingly being used to research a wide range of topics (e.g. Bradshaw et al. 2001; Madsen and Adriansen 2004; Winchester 1999). Although many of the associated methodological discussions focus on the challenges of combining qualitative and quantitative approaches, the mixing of various interpretive and participatory methods also raises key ethical and methodological issues for researchers. These issues are of current importance to researchers in children's geographies, where 'child-centred' methods are often used in tandem with techniques such as participant observation and semi-structured interviews to capture the complexity and diversity of children's values, perceptions and experiences (e.g. Langevang 2007; Leyshon 2002; Rawlins 2006). In employing such a mixed-method qualitative approach, however, children's geographers often fail to recognise the resultant myriad of shifting power relations between the adult researcher and the child participant. It is therefore important that we reflect on some of the issues that arise for both the researcher and the research participants when combining methods in this way, as well as the potential benefits of using mixed methods. This undertaking will be useful not only for children's geographers, but also human geographers generally and researchers in other disciplines who wish to make use of mixedmethod qualitative approaches.

In this article, I will begin by outlining the nature of power in social research with children, followed by an exploration of the different power dynamics between adult researchers and child participants in ethnographic participant observation, semi-structured interviews and participatory child-centred methods. I will then briefly discuss the concept of triangulation 
or 'crystallisation', before exploring some of the issues in more depth through reference to an empirical case study on research into children's perceptions of health, sport and active play in the spaces of the primary school. In the conclusion, I will argue that mixing qualitative methods can be beneficial for gaining deeper and more complex understandings of social processes, but that a reflexive approach is required in order to deal with the challenges of combining different methodological approaches.

\section{Power and 'crystallisation' in research with children}

Social research with children has tended to 'position' children in different roles as part of the research process, based on particular cultural assumptions about their levels of competence, vulnerability and powerlessness in society (see Christensen and Prout 2002; Morrow and Richards 1996). However, Christensen reminds us that 'in the process of research, power moves between different actors and different social positions, it is produced and negotiated in the social interactions of child to adult, child to child and adult to adult in the local settings of the research' $(2004,175)$. In other words, power is actually about the process of research and the continually shifting power relations between researcher and research subject. In order to understand these effectively, it is necessary to consider carefully what we actually mean by 'adult researcher' and 'child participant' in different contexts, and to examine the fluid nature of power relations in constructing knowledge using particular research methods. In this section, I will explore these issues in relation to three different research methods: participant observation, semi-structured interviews and 'child-centred' methods, before considering how the methods might usefully be combined using triangulation or 'crystallisation'. 


\section{Ethnographic participant observation}

Brewer defines ethnography as 'the study of people in naturally occurring settings or 'fields' by methods of data collection which capture their social meanings and ordinary activities, involving the researcher participating directly in the setting, if not also the activities, in order to collect data in a systematic manner but without meaning being imposed on them externally' $(2000,6)$. Participant observation therefore involves the researcher immersing his or herself in the social setting and recording through field notes and 'thick description' (Geertz 1973), interesting observations about the area of study (Pole and Morrison 2003). The approach is, however, internally diverse and its various versions have been influenced by positivism, humanism, realism and postmodernism. For example, in the model of humanistic ethnographic research, the researcher seeks to accurately reproduce the views of the 'insider' or the 'other' (Brewer 2000). In contrast, postmodern ethnography insists that reality is constructed through the process of participation and research, rather than merely being 'out there' to collect (Hammersley and Atkinson 1995).

Central to participant observation is the development of relationships between researcher and participants, through everyday events and interaction (Burgess 1984; Van Maanen 1988). In the case of research with children, ethnographers have in the past attempted to remove power differences in these relationships by trying to 'blend in' with children's worlds (e.g. see Mandell 1991). Increasingly, however, the complexities of the power relations between adult ethnographers and child participants are being accepted as inevitable and unavoidable (James 2001). Instead, researchers are adopting a reflexive 
approach to ethnographic research with children, including considering their own role in the field and its impact on children's everyday worlds (see Emond 2005). This has included the practice of adopting semi-adult roles such as 'adult friend' (see Fine and Sandstrom 1988) in order to reduce power disparities, while still accepting their existence. Despite these different strategies, power relations between adults and children are always in continual flux in the field. Corsaro (2003) discovered this when he was asked by a teacher to carry out the job of 'toilet monitor' and had to find a way to persuade a class of children to follow his instructions when they refused to recognise him as an adult with authority.

\section{Semi-structured interviews}

Semi-structured interviews can be defined as 'conversations with a purpose' (Burgess 1984 in Mason 2002), and generally start from a number of predetermined questions or topics, but then adopt a flexible approach for discussion with the interviewee. Kvale argues that 'the qualitative research interview attempts to understand the world from the subjects' points of view, to unfold the meaning of people's experiences, to uncover their lived world prior to scientific explanations' $(1996,1)$. As with ethnography, the approach is internally diverse and has been influenced by a variety of philosophical traditions. More recently, postmodernism has influenced a conception of the research interview as an active social encounter, where knowledge is constructed through the interaction of interviewer and interviewee (Holstein and Gubrium 1995; Kvale 1996).

The relationship between the researcher and the participant is considered just as important in semi-structured interviewing as in ethnography (see Oakley 1981) and its significance has 
increased following the acknowledgement that the data itself is constructed as a result of this relationship. Power is again under the spotlight, particularly in the case of research with children, where culturally constructed power differentials are usually present. Like in ethnography, researchers have attempted to find techniques to lessen these differentials, while still acknowledging their presence. Aware of the uneven power relations in her own research, for example, Mayall (2000) developed a technique of 'research conversations', where children chose partners to be interviewed with, giving them more confidence to make inputs into the interview agenda. Similarly, Westcote and Littleton (2005) discuss the need to empower children during interviews so as to avoid the usual model of teacher initiation-child response-teacher feedback process that children expect from adults. Again, these power relations are not fixed but constantly changing in the spaces of the research. Christensen (2004) reports how, in her taped interviews with children, they would often disrupt the normal power relations of the interview by grabbing the tape recorder and asking her questions.

\section{Participatory 'child-centred' methods}

Participatory research is effectively a hybrid of different research methods that have been developed for diverse purposes (Pretty et al. 1995). Kemmis and McTaggart (2003) characterise such research as practical, collaborative and emancipatory. Pain argues that 'participatory approaches lend themselves to research where people's relations with and accounts of space, place and environment are of central interest' $(2004,653)$, so highlighting their suitability for research in social geography, particularly in giving voice to marginal groups and challenging social exclusion. Cornwall and Jewkes (1995) emphasise 
the way that participatory research works much more as a 'bottom-up' process, with participants contributing their own local priorities and perspectives.

Pain and Francis (2003) make the distinction between 'participatory diagramming', which involves the use of participatory methods of data generation, and 'participatory approaches', which aim to transform power relations between researchers and participants. In participatory research on children and childhoods, this concept has been illustrated through the idea of rungs on a ladder, with each rung indicating more involvement and participation for children (Hart 1992 cited in Alderson 2000, 248). At one end of the continuum is the use of creative 'child-centred' research methods. These methods are generally aimed at reconstituting power relations between adult researchers and child participants at the data generation phase. Veale (2005) defines creative methods as 'those that draw on inventive and imaginative processes, such as storytelling, drama and drawing' $(2005,254)$.

Some participatory methods go beyond child-centred methods however, by involving children in different parts of the research process. Alderson (2000) points out that children have extensive experience of undertaking small research projects at school, and there are examples of studies where children have been involved in different stages of the research process such as planning, analysis and dissemination (e.g. Jones et al. 2002; Jones 2004). These situations require the researcher to adopt a new role, involving the development of new skills in order to manage and facilitate the research (see, for example, Boog 2003; Cornwall and Jewkes 1995; Chataway 1997). For O'Kane (2000), participatory techniques with children imply a more defined relationship between researcher and research subject, a 
more delineated time period and a more transparent process than in ethnographic research. They therefore offer greater potential for a destabilisation of adult-child power relations than in ethnographic or semi-structured interview research.

\section{Triangulation and 'crystallisation'}

Triangulation is a technique that emerged as a response to criticism of qualitative approaches from positivist researchers, particularly the charge that such approaches lack appropriate validity (see Blaikie 2000). The concept draws on the metaphor from surveying and navigating, where a single unknown location is found at the point where the trajectories from three known locations meet (Hammersley and Atkinson 1995). Denzin (1989) argued that using triangulation could improve the validity of research findings by directing a range of different methods at the same problem, and checking whether or not they all returned similar results. This conception of triangulation has been criticised by writers such as Flick (2002), who points out that different methods have developed from different ontological and epistemological traditions and so cannot necessarily be used together to investigate the same dimension of a problem. Richardson (1994) adds a postmodern twist to this, arguing that because of the constructed nature of reality, any employment of mixed methods can only ever produce a partial view of the research topic. She prefers the use of the term 'crystallisation', rather than triangulation, in order to recognise that there are more than three sides to the world, and that mixing methods can only produce a deeper and more complex view of the issue under investigation, rather than improve validity. 
Darbyshire et al.(2005) consider whether or not using 'crystallisation' does in practice offer deeper insights and increased complexity by reference to an empirical study on children and physical activity in place and space. They found that the different data methods of focus group interviews, mapping and photography actually worked to complement each other and build up a more holistic picture of children's perspectives, rather than merely duplicate findings. For example, some important physical activities for children were only identified in certain methods and children's feelings and emotions were better represented in some sets of data than others. In contrast, researchers may find that data generated through the use of different research methods actually contradict, rather than complement each other. Instead of viewing this as a negative feature of using mixed methods, the scenario offers an opportunity to better understand the complexities of social life, and avoid the presentation of 'easy' conclusions that 'gloss over' some of the hidden difficulties that mixed methods may reveal. It may also point to the need for further research that attempts to untangle some of the multifaceted social processes revealed in the original study.

Combining participant observation and semi-structured interviews in research with children is a good way of working towards the aim of 'crystallisation', as it allows the researcher to investigate both the 'doing' and how children represent these 'doings' through talk. Both data types are co-produced and constructed actively through the relationships between researcher and participant (Atkinson and Coffey 2003). Adding the extra perspective of participatory 'child-centred' methods potentially brings more of children's own priorities and interpretations to the data, particularly if they are involved in the planning, analysis and representation stage of the research. In the next section, I explore how combining 
these three methods worked out in practice as part of an empirical research study, particularly in terms of the changing power relations between adult researcher and child participants, and the ways in which the different data sets both complemented and contradicted each other.

\section{Mixing qualitative methods in practice}

The research project in question aimed to investigate health and exercise in the everyday spaces of a UK primary school (see also Hemming 2007). Participants were aged 9-10 years and the mixed methods included ethnographic observation and interview techniques, which focused particularly on the children's experiences, as well as 'child-centred' participatory methods, which were aimed more at exploring the children's values. The observation took place over a full-time period of three weeks and included spending time with children in both the classroom and the playground. In the classroom, I worked as a general helper, observing lessons and responding to children's queries and requests for help with their schoolwork, while on the playground I tended to wander around watching the activities and chatting informally to the children. The semi-structured interviews were adapted to make them short in length and included visual images to stimulate the children's ideas.

Participants were interviewed in pairs (chosen by the children) and they were given traffic light cards to control the progress of the interviews, with red indicating 'stop', amber 'short pause' and green 'go' (see Alderson and Morrow 2004). Alongside these more traditional techniques, two specifically designed creative 'child-centred' methods were used to investigate the children's perceptions of 'healthy' and 'unhealthy'. All three of the different 
data sets were analysed thematically (see Attride-Stirling 2001), to allow them to be integrated more easily at the level of explanation (see Mason 2002).

The first 'child-centred' activity was an individual drawing task based on methods from Wetten and McWhirter (1998) and Burrows and Wright (2004) but was given a different twist by using the popular 'Mr. Men' and 'Little Miss' children's book series by Roger Hargreaves as a stimulus. The children were asked to draw a picture of a 'Mr. Healthy' and 'Mr. Unhealthy' or the 'Little Miss' equivalents and included a picture of the character, a setting and associated objects around the picture, and written labels to clarify the content of the drawings. For the second activity, the children were asked to work in groups of their own choosing to think about the five most important places in the school that were 'healthy' and five most important places that were 'unhealthy'. The children were then asked to take photographs of each place using disposable cameras and then record their reasoning for the choices of the group, as well as an adjective to describe the photograph. This was an attempt to involve children in the initial analysis of the data. The activity was based on ideas from Scratz and Steiner-Loffler (1998), although with a different subject focus. These methods did involve children more in the data collection stage, but were not fully participatory at the other stages of the research. This was mainly due to the practical and time constraints of undertaking a small-scale research project, as well as the inherent difficulties in involving children from schools in planning and dissemination, such as the nature of the research planning process and gaining access through gatekeepers (see Pole et al. 1999). 


\section{Changing power relations}

The data generation stage was the main point at which the three research methods met and where the different relationships between the children and myself had to be negotiated. Maintaining a mainly passive participant observer role in the classroom (see, for example, Corsaro 2003), building up close research relationships with the children in order to facilitate relaxed interviews (see, for example, Mayall 2000) and adopting a coordinating role in order to facilitate and manage the children during 'child-centred' methods (see, for example, O'Kane 2000) are all very different. The latter role in particular seemed to be incompatible with the other methods. Aware of the difficulties of juggling these dual roles, I felt it would be most appropriate to carry out observation and interviews before the 'childcentred' activities. I hoped that this would help to avoid the more authoritative coordinator role undermining my efforts to observe the children in their everyday contexts or to encourage the children to feel relaxed and comfortable talking to me during interviews.

During the participant observation, considerable time was spent helping in the class so that the children would feel comfortable around me, partly in preparation for the interviews, and also to reduce the impact of my presence on the children's usual behaviour. Anxious to avoid being seen as a teacher, I deliberately dressed more casually than the teachers in the school and tried to distance myself from any situations where I might have been required to express any authority. The outcomes of this approach were illustrated through the way that children in the class asked me to take part in their playground games, such as skipping, and felt able to confide in me, for example regarding issues of bullying that were already being handled by the school. It also provided a space in the semi-structured interviews that 
enabled the children to express their views and opinions. During the interviews, children felt able to use short conversations between themselves in order to move the interview on in creative ways, thus disrupting the usual model of adult-directed interaction in school.

INTERVIEWER:

Why don't you play [football] as much as the boys do, do you think?

FLEUR:

'Cos they're boys.

ZOE:

I do like football.

FLEUR:

And they like football, and like girls don't. They like make-up and stuff.

INTERVIEWER:

Ok.

ZOE:

I do play a lot of football with my friends, like friends.

FLEUR:

Yeah but that's only to attract the boys.

ZOE:

(laughs) No it's not.

FLEUR:

That's what some people thought. 
Once the ethnographic part of the fieldwork and the interviews had been completed, I was able to switch roles for the 'child-centred' activities into a research facilitator. The new role was necessarily more authoritative than the role I adopted for the ethnographic part of the study, as it involved managing a class of almost 30 children to successfully carry out a range of practical tasks both in the classroom and around the school. The decision to separate the two parts of the fieldwork in this way proved to be necessary when, during the 'childcentred' activities, one of the children in the class asked me whether or not I was a teacher. I replied truthfully that I had been in the past, although my admission came after all the interviews were finished, thus avoiding any possibility that this would affect the interview data.

Negotiating the two different roles during the data generation phase was not just about timing. Connolly (2008) has written about how his status as a white male adult in a primary school, populated mainly with children and female teachers, impacted upon the network of power relations in the research space. He explores the way that children in his study responded to his social identity by, for example, sexualising conversations, and renegotiating their culturally ascribed subject status as powerless and incompetent children (see also Corsaro 2003). Masculinity was also central to the way that power relations between the children and myself were played out in the different research methods used. I found that the observer, interviewer and participatory researcher roles all required different ways of presenting myself, and actually constituted different ways of 'performing' my masculinity. If gender can be viewed as something that an individual does my masculine identity during fieldwork can also be understood as an embodied performance (see Butler 1990; McDowell and Court 1994). 
Vanderbeck (2005) discusses some of the issues confronting male researchers who do not conform to dominant masculine ideals, including the way that masculine identities may come under scrutiny by research participants. As someone who also fails to identify with many of the hegemonic expectations of masculinity, I experienced similar scrutiny during the ethnographic research from many of the boys in the class who were shocked that I didn't support a football team and took a rather dismissive attitude towards me after discovering this. On the other hand, I was much more comfortable and relaxed adopting this role in the school context and believe that my 'softer' masculine identity in some ways helped to build up more positive research relationships with the children during interviews, although girls were often much more forthcoming than boys. Taking on the role of facilitator of group activities during the 'child-centred' research resulted in a very different performance of masculinity however. Coordinating a large class of children during group activities requires a certain amount of authoritativeness, and the more hegemonic 'masculine' characteristics that I was required to demonstrate resulted in a more positive response from most of the boys in the class, particularly during the photography activity.

Adopting a more authoritarian role during the 'child-centred' research methods also raised other power issues in the context of the classroom, within implicit discourses of education and schooling. David et al. (2001) outline how their attempts to give children the opportunity for informed consent in a classroom context resulted in reinforcing unequal adult-child power relations through their use of implicit pedagogic techniques. While this example also refers to the debate over whether children can 'consent' or merely 'assent' in social research (e.g. see Valentine 1999; Cocks 2006), it also highlights some of the power 
issues that may arise when participatory researchers work in institutional contexts. During the study, I did not see how the participatory child-centred methods were particularly more empowering for the children than the adapted ethnographic and interview techniques, precisely because of my more authoritarian role. Although this perception may have been affected by the lack of children's involvement in other stages of the research process, I found that the 'child-centred' methods were merely a different way of co-producing data with children than the ethnographic and interview techniques. It was therefore a case of different forms of, rather than different levels of, participation for children.

\section{Complementary and contradictory data}

Integrating three data sets through 'crystallisation' potentially offers a more complex perspective on a problem, but data gathered from different methods may be complementary or contradictory, and in the case study, there were examples of both of these scenarios. Standing alone, the 'child-centred' methods indicated that children drew clear distinctions between 'healthy' as positive and 'unhealthy' as negative. For example, 'Little Miss Healthy' and 'Mr. Healthy' for children showed positive physical and mental attributes such as smiles, thin or strong bodies and pretty or trendy clothes, hair and jewellery (see also Burrows and Wright 2004). Similarly, 'healthy places' identified included places where sport and games took place, such as the playground, where healthy food was eaten, or places associated with nature, fresh air and open spaces, such as the garden and field (see Figure 1). Healthiness was thus viewed as a positive virtue that reflected other positive aspects of an individual's personality, or as something connected with the 'rural idyll', where nature is associated with children's health (see Jones 1997). 

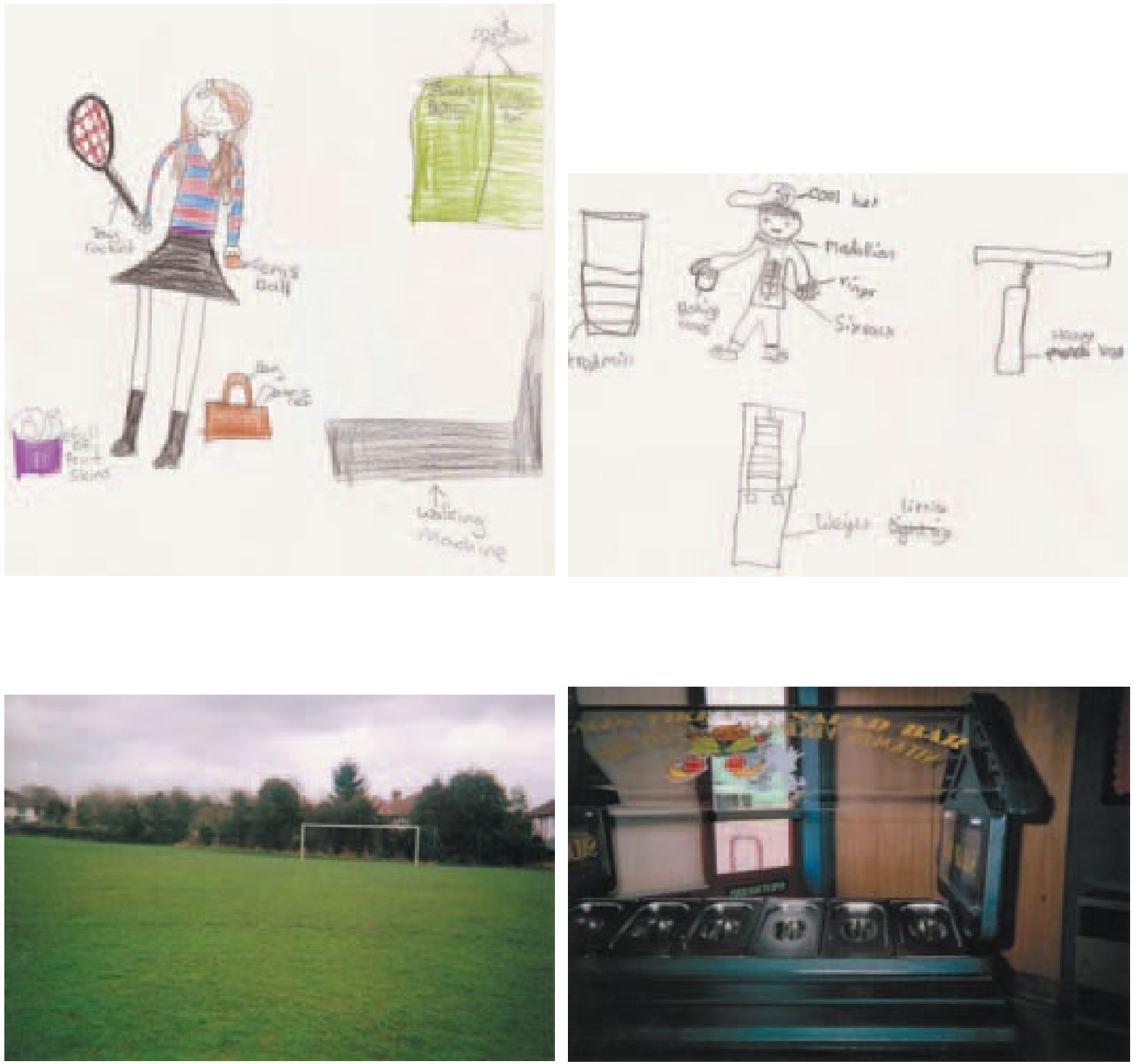

Figure 1: Healthy people and places

In contrast, 'Little Miss Unhealthy' and 'Mr. Unhealthy' displayed lazy, untidy and dirty personal attributes such as smelly bodies, stained clothes and messy houses. Similarly, 'unhealthy places' included sites for eating unhealthy foods or doing sedentary activities, and places such as dusty store cupboards, smelly bins and dirty toilets (see Figure 2). The 
emphasis placed on dirt links with Sibley's (1995) observations on exclusion. He argues that 'exclusionary discourse draws particularly on colour, disease, animals, sexuality and nature, but they all come back to the idea of dirt as a signifier of imperfection and inferiority' (1995, 14). 'Unhealthiness' was thus viewed as a 'negative' individual personality trait, and unhealthy people as 'other'.
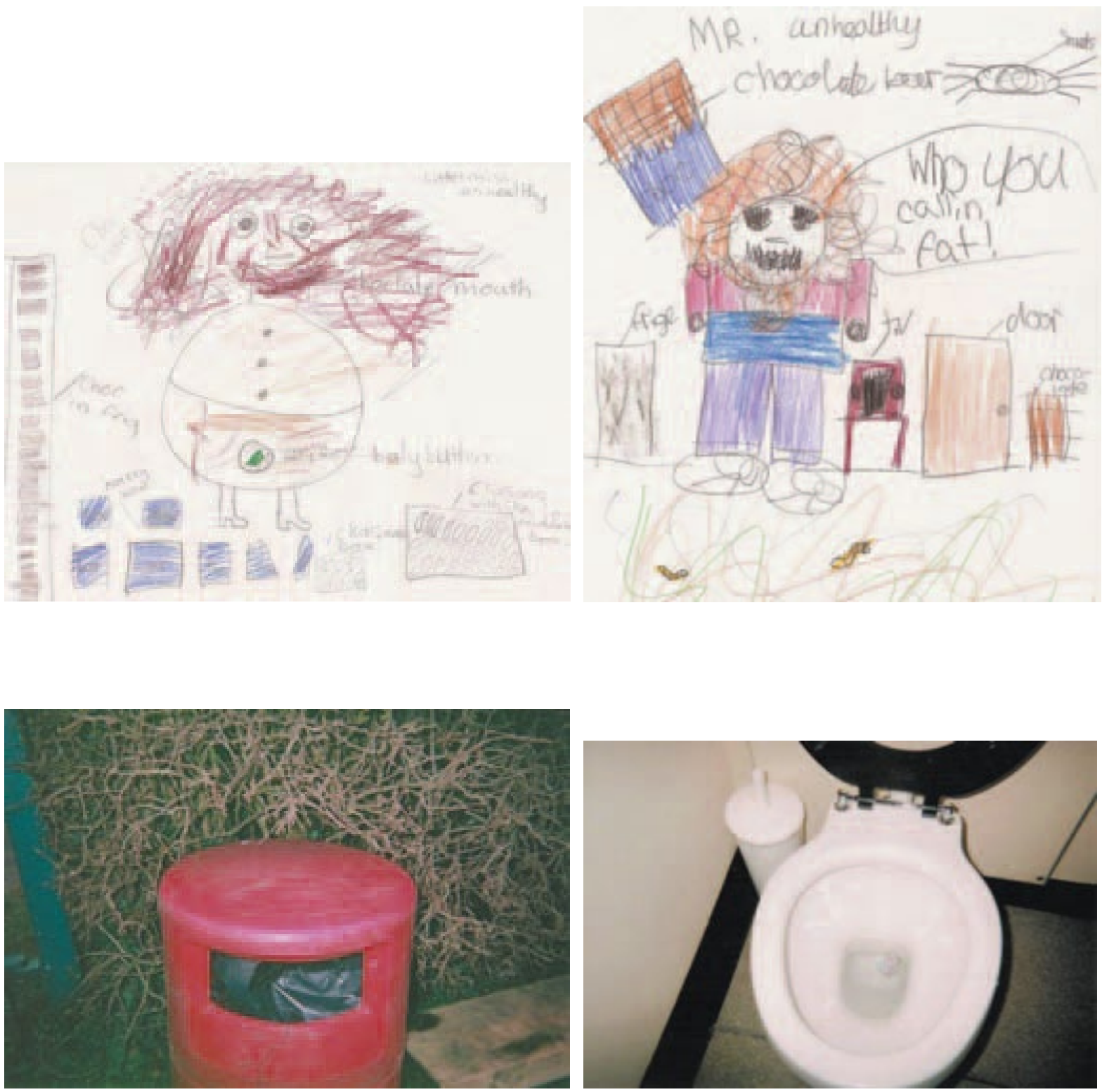

Figure 2: Unhealthy people and places 
In some ways, the interviews and observations were able to show how children's everyday experiences helped to reinforce their perception of 'healthy' as positive, thus complementing the 'child-centred' methods. Children's encounters with sport, exercise and active play were often reported in the interviews as fun, pleasurable and enjoyable (see also Burrows et al. 1999; Mulvihill et al. 2000; Tuxworth 1997). My observations also confirmed the way that many of these activities were associated with enjoyment, although this was structured through factors such as gender and peer group influences. Discourses of exercise as 'fun' were often intertwined with ones of health in the interviews (see also Macdonald et al. 2005). This again helped to strengthen the idea of 'healthy' as a positive thing that complemented the results from the participatory 'child-centred' methods.

\section{INTERVIEWER:}

OK do you do those things because they are healthy or do you do them for another reason?

CHLOE:

I do 'em 'cos they're fun.

INTERVIEWER:

Ok.

YASMIN:

I do them because they are healthy.

CHLOE:

Well I do it because it's just kind of... CHLOE and YASMIN: 
Fun.

In the case of 'unhealthy', however, there was a certain amount of contradiction between the data sets. In the interviews, children talked about how much they liked taking part in unhealthy activities such as eating sweet or fatty foods and playing sedentary video games, and some of these admissions were again backed up by my observations. Children's views on health were therefore somewhat more complex than the participatory data had indicated, because although the pictures demonstrated a good understanding of health issues, children's decisions demonstrated a clear gap between knowledge and behaviour (see also Lupton 1996; Warwick et al. 1999). The ethnographic and interview data showed that for children 'unhealthy' was not as negative as the 'child-centred' visual data had suggested, so highlighting the need for both sets of data in order to reach a deeper understanding of children's ideas and perceptions.

\section{INTERVIEWER:}

Ok so why did you decide to watch the TV or eat chocolate?

STEVEN:

'Cos chocolate's nice.

INTERVIEWER:

Ok.

STEVEN:

And TV's good. 
The mixed-method approach, as well as exploring both values and experiences surrounding health and exercise, actually helped to highlight some of the ways in which these values and experiences were intertwined. Although children's experiences of sport and active play helped to reinforce their idea of 'healthy' as inherently positive, talking about their unhealthy pursuits revealed certain contradictions between their experiences of such activities and the knowledge they had accumulated inside and outside of school about 'unhealthy' as a negative concept. Using the three methods together through the technique of 'crystallisation' created a deeper and more complex understanding of the topic under investigation - something that equalled more than the sum of its parts.

\section{Conclusion}

Using mixed methods in children's geographies is an attractive pursuit, potentially providing new insights and understandings into children's worlds and the issues that affect them on a day-to-day basis. This paper has illustrated how using a combination of ethnographic participant observation, adapted semi-structured interviews and participatory 'childcentred' methods allowed for a deeper and more complex understanding of children's experiences and perceptions of health and exercise in the spaces of the primary school. On the other hand, combining methods can also raise ethical and methodological issues, particular relating to the changing power relations between the adult researcher and the child participant. In the example explored in this paper, my role as a researcher, and the way in which the children related to me, continually fluctuated as different research methods and their associated power relations intersected with each other. Each method 
allowed for the co-production and active construction of data in slightly different ways, with varying forms of participation for children in each case.

Focusing on the mixing of qualitative methods has also highlighted some wider issues about power and the categories of 'adult' and 'child'. The ways that power relations were continually changing, both within and between different research methods, points to the fluid nature of such power relations, and the way that power is actually constituted through relationships (see Christensen 2004; Thomson 2007). It also underlines the way that the social roles and identities of children and adults cannot be taken as given, whether in the context of geographical research, or any other social space. As Thomson argues, 'identities are multiple, fluid in nature and continually negotiated within and through space' (2007, 214), including the performed identities of children and adults in the research space. This is something that becomes increasingly obvious through the employment of mixed methods in research with children.

As human geography begins to engage more with mixed-method approaches, researchers may well find themselves facing new ethical and methodological challenges in the field, but also opportunities to gain new understandings of their subject of inquiry. As part of this process, it is important that geographers both reflect carefully during the planning stages of their research and act reflexively in the field to overcome difficulties. Recording and documenting these decisions will not only add to the quality of research, but also offer practical advice to others who are working on similar projects. Mason (2006) offers a good general approach to mixing methods in her argument for the 'meshing' or 'linking' of data from different methods in a 'qualitatively driven way'. By valuing the creativity, richness and 
complexity that mixed methods bring to social research, the reflexivity and flexibility of the qualitative approach offers a framework in which to develop new and deeper explanations from a range of different research methodologies. Such innovative approaches to the mixing of methods promise human geographers the opportunity to gain new perspectives on a wide range of substantive research areas.

\section{Acknowledgements}

I would like to thank Robert Vanderbeck and the anonymous referees for helpful comments on earlier drafts of the article, and Gill Valentine and Sarah Irwin for their advice and support during the research project on which this article draws. I am grateful to ESRC for the opportunity to have undertaken the study. Many thanks also to all the staff and children at the case study school who contributed to the research.

\section{References}

Alderson P 2000 Children as researchers: the effects of participation rights on research methodology in Christensen P and James A eds Research with children: perspectives and Practice Falmer, London 241-57

Alderson P and Morrow V 2004 Ethics, social research and consulting with children and young people Barnado's, Iford 
Atkinson P and Coffey A 2003 Revisiting the relationship between participant observation and interviewing in Holstein J and Gubrium J F eds Inside interviewing: new lenses, new concerns Sage, London 415-28

Attride-Stirling J 2001 Thematic networks: an analytical tool for qualitative research Qualitative Research 1 385-405

Blaikie N 2000 Designing social research Polity, Cambridge

Boog B W M 2003 The emancipatory character of action research, its history and the present state of the art Journal of Community and Applied Social Psychology 13 426-38

Bradshaw M, Wood L and Williamson S 2001 Applying qualitative and quantitative research: a social impact assessment of a fishery Applied Geography 21 69-85

Brewer J D 2000 Ethnography Open University Press, Buckingham Burgess R G 1984 In the field: an introduction to field research Routledge, London Burrows C, Eves F and Cooper D M 1999 Children's perceptions of exercise - are children mini-adults? Health Education 99 61-9 
Burrows L and Wright J 2004 The good life: New Zealand children's perspectives on health and self Sport, Education and Society 9 193-205

Butler J P 1990 Gender trouble: feminism and the subversion of identity Routledge, London

Chataway C J 1997 An examination of the constraints on mutual inquiry in a participatory action research project Journal of Social Issues 53 747-65

Christensen P 2004 Children's participation in ethnographic research: issues of power and representation Children and Society 18 165-76

Christensen P and Prout A 2002 Working with ethical symmetry in social research with children Childhood 9 477-97

Cocks A J 2006 The ethical maze: finding an inclusive path towards gaining children's agreement to research participation Childhood 13 247-66

Connolly P 2008 Race, gender and critical reflexivity in research with young children in Christensen P and James A eds Research with children: perspectives and practices 2 nd edn Routledge, London

Cornwall A and Jewkes R 1995 What is participatory research? Social Science and Medicine 41 1667-76 
Corsaro W A 2003 We're friends right? Inside kid's culture Joseph Henry, Washington DC

Darbyshire P, Macdougall C and Schiller W 2005 Multiple methods in qualitative research with children: more insight or just more? Qualitative Research 5 417-36

David M, Edwards R and Alldred P 2001 Children and schoolbased research: informed consent or educated consent? British Educational Research Journal 27 347-65

Denzin N K 1989 The research act: a theoretical introduction to sociological methods McGraw-Hill, New York

Emond R 2005 Ethnographic research methods with children and young people in Greene S and Hogan D eds Researching children's experience: approaches and methods Sage, London 123-39

Fine G A and Sandstrom K L 1988 Knowing children: participant observation with minors Sage, London

Flick U 2002 An introduction to qualitative research 2nd edn Sage, London

Geertz C 1973 The interpretation of cultures Basic Books, New York

Hammersley M and Atkinson P 1995 Ethnography: principles in practice 2nd edn Routledge, London 
Hemming P J 2007 Renegotiating the primary school: children's emotional geographies of sport, exercise and active play Children's Geographies 5 353-71

Holstein J A and Gubrium J F 1995 The active interview Sage, London

James A 2001 Ethnography in the study of childhood in Atkinson P, Coffey A, Delamont S, Lofland J and Lofland L eds Handbook of ethnography Sage, London 246-57

Jones A 2004 Involving children and young people as researchers in Fraser S, Lewis V, Ding S, Kellett M and Robinson C eds Doing research with children and young people Sage, London $113-30$

Jones A, Jeyasingham D and Rajasooriya S 2002 Invisible families: the strengths and needs of black families in which young people have caring responsibilities Policy Press and Joseph Roundtree Foundation, Bristol

Jones O 1997 Little figures, big shadows: country childhood stories in Cloke P and Little J eds Contested countryside cultures: otherness, marginalisation and rurality Routledge, London $158-79$

Kemmis S and McTaggart R 2003 Participatory action research in Denzin N K and Lincoln Y S eds Strategies of qualitative inquiry 2 nd edn Sage, London 336-96 
Kvale S 1996 InterViews Sage, London

Langevang T 2007 Movements in time and space: using multiple methods in research with young people in Accra, Ghana Children's Geographies 5 267-82

Leyshon M 2002 On being 'in the field': practice, progress and problems in research with young people in rural areas Journal of Rural Studies 18 179-91

Lupton D 1996 Food, the body and the self Sage, London

Macdonald D, Rodger S, Abbott K, Ziviani J and Jones J 2005 'I could do with a pair of wings': perspectives on physical activity, bodies and health from young Australian children Sport Education and Society 10 195-209

McDowell L and Court G 1994 Performing work: bodily representations in merchant banks Environment and Planning D: Society and Space $12727-50$

Madsen L M and Adriansen H K 2004 Understanding the use of rural space: the need for multi-methods Journal of Rural Studies 20 485-97

Mandell N 1991 The least-adult role in studying children in Wakster F ed Studying the social worlds of children Falmer, London 38-59

Mason J 2002 Qualitative researching 2nd edn Sage, London 
Mason J 2006 Mixing methods in a qualitatively driven way Qualitative Research 6 9-25

Mayall B 2000 Conversations with children: working with generational issues in Christensen P and James A eds Research with children: perspectives and practices Routledge-Falmer, London 120-35

Morrow V and Richards M 1996 The ethics of social research with children: an overview Children and Society 10 90-105

Mulvihill C, Rivers K and Aggleton P 2000 A qualitative study investigating the views of primary-age children and parents on physical activity Health Education Journal 59 166-79

Oakley A 1981 Interviewing women: a contradiction in terms in Roberts H ed Doing feminist research Routledge and Kegan Paul, London 30-61

O’Kane C 2000 The development of participatory techniques: facilitating children's views about decisions which affect them in Christensen P and James A eds Research with children: perspectives and practices RoutledgeFalmer, London 136-59

Pain R 2004 Social geography: participatory research Progress in Human Geography 28 65263

Pain R and Francis P 2003 Reflections on participatory research Area 35 46-54 
Pole C and Morrison M 2003 Ethnography for education Open University Press, Maidenhead

Pole C, Mizen P and Bolton A 1999 Realising children's agency in research: partners and participants? International Journal of Social Research Methodology 2 39-54

Pretty J N, Guijt I, Thompson J and Scoones I 1995 Participatory learning and action: a trainer's guide International Institute for Environment and Development, London

Rawlins E 2006 Mother knows best? Intergenerational notions of fashion and identity Children's Geographies 4 359-77

Richardson L 1994 Writing: a method of inquiry in Denzin N K and Lincoln Y S eds Handbook of qualitative research Sage, Thousands Oaks CA 444-62

Scratz M and Steiner-Loffler U 1998 Pupils using photographs in school self-evaluation in Prosser J ed Image-based research: a sourcebook for qualitative researchers RoutledgeFalmer, London 235-51

Sibley D 1995 Geographies of exclusion: society and difference in the West Routledge, London

Thomson F 2007 Are methodologies for children keeping them in their place? Children's Geographies 5 207-18 
Tuxworth B 1997 The St. Edmundsbury fitness survey 1993-1995 St Edmundsbury Borough Council, Bury St Edmunds

Valentine G 1999 Being seen and heard? The ethical complexities of working with children and young people at home and at school Ethics, Place and Environment 2 141-55

Van Maanen J 1988 Tales of the field: on writing ethnography University of Chicago Press, Chicago IL

Vanderbeck R M 2005 Masculinities and fieldwork: widening the discussion Gender, Place and Culture 12 387-402

Veale A 2005 Creative methodologies in participatory research with children in Greene S and Hogan D eds Researching children's experience: approaches and methods Sage, London $253-72$

Warwick J, Mcllveen H and Stugnell C 1999 Food choices of 9-17 year olds in Northern Ireland: influences and challenges Nutrition and Food Science 99 229-36

Westcote H L and Littleton K S 2005 Exploring meaning in interviews with children in Greene S and Hogan D eds Researching children's experience: approaches and methods Sage, London 141-57 
Wetten N M and McWhirter J 1998 Images and curriculum development in health education in Prosser J ed Image based research: a sourcebook for qualitative researchers RoutledgeFalmer, London 263-83

Winchester H P M 1999 Interviews and questionnaires as mixed methods in population geography: the case of lone fathers in Newcastle, Australia Professional Geographer 5160 7 